Article

\title{
Efficacy of Combinations of Methoprene and Deltamethrin as Long-Term Commodity Protectants
}

\author{
Frank H. Arthur
}

USDA, Agricultural Research Service, Center for Grain and Animal Health Research, 1515 College Avenue, Manhattan, KS 66502, USA; frank.arthur@ars.usda.gov

Received: 13 December 2018; Accepted: 31 January 2019; Published: 5 February 2019

Abstract: Wheat, corn, and brown rice were treated with different combinations of a deltamethrin suspension concentrate (SC) formulation and a new emulsifiable concentrate (EC) formulation, at rates of either 0.5 or $1.0 \mathrm{ppm}$ alone or in combination with 1.25 and $2.5 \mathrm{ppm}$ methoprene (10 treatments in all, including an untreated control). Treated commodities were stored at ambient conditions on the floor of an empty grain bin in Manhattan, KS, USA, in 5-kg lots for individual replicates. The commodities were sampled and bio-assayed every three months for 15 months by exposing 10 mixed-sex parental adults of selected adult stored product insects on $70-80 \mathrm{~g}$ of the commodity. For all treatments, there was no regression of declining efficacy with respect to the month. Therefore, the data were combined for analysis. On wheat and brown rice, there was no reproduction of Rhyzopertha dominica (Fabricius) in any of the treatments, and there was no weight loss in either commodity that was caused by feeding of the parental adults or developing progeny. There was reproduction of Sitophilus oryzae (L.) on wheat but, for several combinations, the EC formulation gave better suppression of progeny compared to the standard SC. However, on brown rice, only the combination of $1.0 \mathrm{ppm}$ deltamethrin EC and $2.5 \mathrm{ppm}$ methoprene was different than other treatments with respect to progeny development, sample weight loss caused by feeding, and weight of the feeding damage itself. Progeny production was correlated with grain damage. No progeny of Tribolium castaneum (Herbst) developed on the treated corn, but there was some variation in insect damage, with less damage in those treatments involving the EC formulation. Progeny production of Sitophilus zeamais (Motschulsky) was at the lowest in the combination of $1.0 \mathrm{ppm}$ deltamethrin EC and $2.5 \mathrm{ppm}$ methoprene. The resulting insect damage was the lowest in this combination as well. Results of this study were used by the registrant (Central Life Sciences) in the United States (US) to modify the commercial formulation to replace the deltamethrin $\mathrm{SC}$ with the EC, at label rates of either 0.5 ppm EC + 1.25 ppm methoprene, or 1.0 ppm EC + 2.5 ppm methoprene, on wheat, corn, and rice.

Keywords: deltamethrin; methoprene; grains; storage; control

\section{Introduction}

When grain crops are harvested and stored, they are vulnerable to infestation from a diverse range of stored product pest insects, which are commonly referred to as either internal feeders, which complete all or most of their life cycle inside the kernel, or external feeders, which exist entirely outside of the kernel [1,2]. Examples of internal feeders include Rhyzopertha dominica (Fabricius), the lesser grain borer, and Sitophilus oryzae (L.), the rice weevil, which are common pests of stored wheat and stored rice in the United States (US) [2]. Infestations can cause economic damage through crop destruction [1,2], feeding damage that results in the loss of milling quality [3], or through rejection as commodities are transported from storage sites to mills and processing plants.

Components of insect pest management programs can include sanitation and cleaning prior to storage, aeration to modify the internal environment of the storage structure, and fumigation 
with phosphine to eliminate infestations that occur during storage [4]. Another viable component of management plans for stored grain management is the use of grain protectants, which are insecticides that are applied as grains and are loaded into storage [5]. In the US, there are a limited number of registered grain protectants, and not all insecticides can be applied to all grain crops [5].

In the US, wheat is harvested during the summer, with harvest times dependent on the geographic location, local conditions, and other biological and environmental factors [6]. In the Southern US, corn can be harvested and stored in late July or early August [7], and, in the south-central rice growing region of the US, the first rice crop can also be harvested and stored in late July and early August as well [8]. Thus, it could be weeks or even months before temperatures are cool enough to use aeration for bin management [6-11]. In addition, in some cases, aeration alone may not be sufficient to manage insect populations in storages located in warmer regions of the US [12,13]. Stored product insects may often be prevalent in the area surrounding grain storages, and serve as an immediate source of infestation [14-16].

The pyrethroid deltamethrin, trade name Centynal ${ }^{\circledR}$, which is a suspension concentrate formulation (SC) was originally registered in the US at a rate of $0.5 \mathrm{ppm}$ on all grain crops. It is highly effective against $R$. dominica, but it may be less effective on $S$. oryzae because longer exposure times are necessary for the control of exposed adults compared to $R$. dominica [17]. Exposed female adults of $S$. oryzae may still be able to oviposit even if they eventually succumb from exposure to deltamethrin [17]. In addition, the insecticidal formulation itself is very thick and viscous and not easy to accurately formulate in water for field applications. A new formulation of deltamethrin was developed, which is an emulsifiable concentrate (EC), that could be combined with the insect growth regulator methoprene (Diacon IGR ${ }^{\circledR}$ ) for potentially enhanced control of R. dominica, S. oryzae, and external feeders. Methoprene will give control of R. dominica and external feeders of stored grains but does not control Sitophilus weevils because they oviposit inside the grain kernel and the developing larvae are not exposed to the insecticidal residues [17]. The purpose of this study was to determine relative efficacy of this new EC formulation with and without the methoprene component, at an increased application rate, for control of stored product insects on wheat, corn, and brown rice.

\section{Materials and Methods}

\subsection{General Information}

This experiment was conducted at the USDA-ARS Center for Grain and Animal Health Research (CGAHR) in Manhattan, KS, USA. There were 10 treatments: the existing SC deltamethrin $\left(\right.$ Centynal ${ }^{\circledR}$, formulation used alone (label rate of $0.5 \mathrm{ppm}$ ) or combined with 1.25 or $2.5 \mathrm{ppm}$ methoprene insect growth regulator (IGR) Diacon ${ }^{\circledR}$, the new deltamethrin EC formulation used alone (at $0.5 \mathrm{ppm}$ and $1.0 \mathrm{ppm}$ ), and each rate combined with 1.25 and $2.5 \mathrm{ppm}$ methoprene). An untreated control was included as well (listed in Table 1). Both deltamethrin formulations contained $50 \mathrm{mg}$ Active Ingredient (AI) $/ \mathrm{mL}$. These formulations were obtained from Central Life Sciences (Schaumberg, IL, USA). The methoprene formulation was $288 \mathrm{mg}(\mathrm{AI}) / \mathrm{mL}$ and obtained from the same location. The treatment combinations are listed in Table 1. The two deltamethrin formulations were abbreviated as EC and SC, for deltamethrin while the methoprene IGR was abbreviated as M, for methoprene.

The insect species used for wheat and brown rice was adults of R. dominica and S. oryzae, while adults of T. castaneum and S. zeamais were used on corn. The R. dominica and S. oryzae used in the study for wheat were obtained from colonies reared on wheat, while the same species used on brown rice were obtained from colonies reared on brown rice. The S. zeamais were obtained from colonies reared on corn, but the T. castaneum used for corn were obtained from colonies reared on a mixture of $95 \%$ whole-wheat flour and Brewers' yeast. All colonies were reared in Percival incubators (Perry, IA, USA) set at $27^{\circ} \mathrm{C}$ and $60 \%$ relative humidity (r.h.), in continual darkness. All colonies had been in culture at the CGAHR for about 30 years. 
Table 1. List of insecticide treatments and abbreviations used in the following tables.

1. UTC, untreated control

2. Suspension Concentrate (SC) formulation of deltamethrin applied at $0.5 \mathrm{ppm}$

3. SC applied at $0.5 \mathrm{ppm}+1.25 \mathrm{ppm}$ methoprene $(\mathrm{M})$

4. SC at $0.5 \mathrm{ppm}+2.5 \mathrm{ppm} \mathrm{M}$

5. EC formulation of deltamethrin applied at $0.5 \mathrm{ppm}$

6. EC applied at $1.0 \mathrm{ppm}$

7. EC applied at $0.5 \mathrm{ppm}+1.25 \mathrm{ppm} \mathrm{M}$

8. EC applied at $0.5 \mathrm{ppm}+2.5 \mathrm{ppm} \mathrm{M}$

9. EC applied at $1.0 \mathrm{ppm}+1.25 \mathrm{ppm} \mathrm{M}$

10. EC applied at $1.0 \mathrm{ppm}+2.5 \mathrm{ppm} \mathrm{M}$

\subsection{Tests with Hard Red Winter Wheat}

The label specifies mixing $270 \mathrm{~mL}$ of the deltamethrin SC or EC in $18.920 \mathrm{~L}$ of water to cover $27,272 \mathrm{~kg}$ of wheat, which is $0.7 \mathrm{~mL}$ of formulated spray $/ \mathrm{kg}$ of wheat. In this study, an individual replicate consisted of $3 \mathrm{~kg}$, which required $2.1 \mathrm{~mL}$ of spray. The rates needed for the study were 0.5 and $1.0 \mathrm{ppm}$. When either the SC or EC formulation was used for an individual replicate, to give these rates of 0.5 and $1.0 \mathrm{ppm}$ either 0.35 and $0.70 \mathrm{~mL}$, respectively, of the parent deltamethrin formulation that was mixed with $25 \mathrm{~mL}$ of distilled water. The $3 \mathrm{~kg}$ of wheat was spread out over a flat piece of cardboard measuring 0.6 by $0.3 \mathrm{~m}$. and $2.1 \mathrm{~mL}$ was pipetted from the volumetric flask and applied using a Badger 100 artist's air brush (Badger Air Brush Company, Franklin Park, IL, USA) attached to a compressor to mist the solution onto the wheat. After the wheat was treated, it was hand-mixed and then poured into an $18.9 \mathrm{~L}$ plastic bucket. The rates of methoprene that were needed for the test were 1.25 and $2.5 \mathrm{ppm}$ or $\mathrm{mg} 1.25$ and $2.5 \mathrm{mg} \mathrm{AI} / \mathrm{kg}$ of wheat. The field volume rate if the insecticide was applied alone was also equivalent to $0.7 \mathrm{~mL}$ of formulated spray per $\mathrm{kg}$, and the label equivalent for 1.25 and $2.5 \mathrm{ppm}$ was 0.15 and $0.3 \mathrm{~mL}$ of the methoprene formulation, respectively, in $25 \mathrm{~mL}$ of water. The deltamethrin and the methoprene amounts from the respective formulation were both mixed in with $0.25 \mathrm{~mL}$ of water to maintain a label equivalent for volumetric application and applied at the rate of $2.1 \mathrm{~mL}$ of formulated spray per the 3-kg of a replicate.

The test was initiated on 15 June 2015. Each treatment was replicated four times by formulating four separate insecticide mixtures to do the application for each of the nine insecticide combinations. A set of four untreated controls of $3 \mathrm{~kg}$ each were sprayed with $2.1 \mathrm{~mL}$ of distilled water. After the wheat was treated, the 40 total buckets containing the various treatments and the replicates were placed on the floor of 27.2 metric ton (MT) capacity grain bin at the CGAHR. The next day, eight samples of about $80 \mathrm{~g}$ were taken from each bucket and placed in each of eight $180 \mathrm{~mL}$ plastic vials with a screen lid. Ten one-two-week-old mixed sex adult $R$. dominica were placed in each of four vials and ten one-two-week-old adult $S$. oryzae were placed in each of the four remaining vials. These vials, in turn, were placed in a walk-in environmental chamber set at $27^{\circ} \mathrm{C}$ and $60 \%$ r.h. and held for about 10 weeks. After this time, the vials were removed from the chamber, and frozen at $-18{ }^{\circ} \mathrm{C}$ to kill all adult insects. After several days, the vials were removed from the freezer and allowed to warm for at least a day on a laboratory counter under ambient conditions. The wheat in each vial was weighed. Then the adult insects were sifted off the wheat and counted. The feeding damage (frass) was collected and weighed, and the sample was weighed again to determine the amount of sample weight loss caused by the insect populations. Data for sample weight loss were converted to percentage values relative to the weight of the original sample. Subsequent bioassays were done every 3 months for 15 months.

\subsection{Tests With Brown Rice}

The brown rice was treated on 5 and 6 October with treatments 1-6 occurring on the 1st, and 7-10 occurring on the 2nd day. Again, the volumetric spray rate for rice was different from that of wheat with $1.9 \mathrm{~mL}$ of formulated spray per the $3 \mathrm{~kg}$. The insecticides were formulated in the $25-\mathrm{mL}$ 
volumetric flasks in accordance with label specifications for treatment on rice. There were four separate replicates for each treatment and commodity. The individual replicates were treated and then held in 19.9 L buckets on the floor of a 27.2 MT capacity empty grain bin at the CGAHR. HOBO computers with cables were placed in an untreated replicate as described for wheat, and samples were taken every 3 months and processed as described for wheat. $R$. dominica and S. oryzae adults were introduced into the sample vials at each bioassay time, as described for wheat.

\subsection{Tests with Corn}

The insecticides were prepared as described for wheat, following the label specifications for treatment of stored corn. The volumetric spray rate is slightly different based on the test weight of corn, so $2.0 \mathrm{~mL}$ of formulated spray was required for $3 \mathrm{~kg}$ of corn. The appropriate amounts of the formulations of deltamethrin and methoprene were mixed in $25 \mathrm{~mL}$ of water and applied to give the desired application rates in terms of specifications for an active ingredient. The corn was treated on 1 and 2 October, treatments 1-6 occurred on the 1st, and 7-10 occurred on the 2 nd. Separate formulations were done for each of the four replicates of each of the 10 treatments. The corn replicates were treated with the airbrush as described for wheat, then placed in $18.9 \mathrm{~L}$ plastic buckets, and the buckets were, in turn, placed on the floor of a different empty 27.2 MT capacity grain bin at the CGAHR. Two HOBO recording computers with cables were set at $7.3 \mathrm{~cm}$ and at $0.30 \mathrm{~cm}$ below the surface in one of the untreated corn replicates. The corn was sampled as described for wheat and insects were added to the vials, except that adults of T. castaneum and S. zeamais were used for this part of the test with corn.

\subsection{Statistical Analysis}

Data were analyzed using the Statistical Analysis System (SAS, version 9.2, Cary, NC, USA). In the first analysis, data were analyzed using the Mixed Procedure to determine if there were significant differences related to months post-treatment for the four variables of analysis, sample weight loss, feeding damage, total weight loss, and progeny production. Although data varied by month and there were significant differences, there was no orderly relationship, i.e., no decline with progeny production or corresponding increase in insect damage, as residues aged (Proc Reg, $p \geq 0.05$ ). Therefore, all data for months were combined for statistical analysis. Orthogonal contrasts were used to conduct pair-wise analyses of select treatments. This was done under the General Linear Models Procedure of SAS to compare the following numbered treatments in Table 1: 1 vs. 2, and 1 vs. 5 to differences between controls and the low rate of $0.5 \mathrm{ppm}$ of the two deltamethrin formulations, 2 vs. 5 to compare 0.5 ppm of the SC and EC formulations, 5 vs. 6 to compare 0.5 and 1.0 ppm of the EC formulation, 7 vs. 10 to compare the $1.0 \mathrm{ppm}$ of the EC formulation with and without methoprene, and 6 versus 10 to compare two EC methoprene combinations.

\section{Results}

\subsection{Hard Red Winter Wheat}

All four variables, progeny adults, sample weight loss, amount of feeding damage (frass), and total weight loss were all significant at $p<0.001$ for $R$. dominica $(F=180.9, \mathrm{df}=9,229, F=5.5, \mathrm{df}=9$, 229, $F=33.3, \mathrm{df}=9,229, F=12.0, \mathrm{df}=9,228$, respectively) under the Mixed model analysis. There was no progeny production of $R$. dominica on wheat in any of the nine treatments during the test except for $1.7 \pm 0.9$ and $1.6 \pm 0.8$ in the SC 0.5 and EC 1.0 ppm deltamethrin treatments, respectively. Frass weight averaged $6.5 \pm 1.1 \mathrm{~g}$ in untreated controls and was $<0.01 \mathrm{~g}$ in all treatments. Total weight loss averaged $19.6 \pm 3.7 \%$ in untreated controls and $<0.01 \%$ in all treatments. Female $R$. dominica lay eggs outside the kernel, and neonate larvae bore inside the kernel and then completed development to the adult stage. Thus, there is an opportunity for the neonates to be exposed to the insecticide residues before they enter the wheat kernel. There was little weight loss, frass production, or total damage in the treated wheat (Table 2). 
Table 2. Progeny production, total weight loss (WL in \%), and feeding damage (Frass wt. in g) (means \pm SE) from exposure of 10 mixed-sex parental adult S. oryzae on untreated wheat and wheat treated with the insecticide combinations in Table 1. $F$ and $P$ values given for selected orthogonal contrasts.

\begin{tabular}{|c|c|c|c|c|c|c|}
\hline & Treatment & $\#$ & Mean $\pm \mathrm{SE}$ & Contrast & $F$ & $p$ \\
\hline \multirow{10}{*}{ Progeny } & Untreated & 1 & $154.4 \pm 16.5$ & & & \\
\hline & SC0.5 & 2 & $52.8 \pm 15.1$ & 1 vs. 2 & 30.9 & $<0.001$ \\
\hline & SC0.5 + M1.25 & 3 & $57.6 \pm 12.2$ & 1 vs. 5 & 11.4 & $<0.001$ \\
\hline & $\mathrm{SC} 0.5+\mathrm{M} 2.5$ & 4 & $36.6 \pm 12.2$ & 2 vs. 5 & 4.4 & 0.036 \\
\hline & EC0.5 & 5 & $91.4 \pm 16.9$ & 5 vs. 6 & 12.7 & $<0.001$ \\
\hline & EC1.0 & 6 & $26.0 \pm 8.2$ & 3 vs. 7 & 0.7 & 0.419 \\
\hline & EC0.5 + M1.25 & 7 & $42.7 \pm 13.8$ & 4 vs. 8 & 0.7 & 0.396 \\
\hline & EC0.5 + M2.5 & 8 & $52.2 \pm 13.5$ & 7 vs. 9 & 4.5 & 0.034 \\
\hline & $\mathrm{EC} 1.0+\mathrm{M} 1.25$ & 9 & $30.1 \pm 12.4$ & 6 vs. 10 & 1.5 & 0.228 \\
\hline & EC1.0 + M2.5 & 10 & $3.7 \pm 2.8$ & 1 vs. 10 & 65.8 & $<0.001$ \\
\hline \multirow{10}{*}{ Total \%WL } & Untreated & 1 & $2.23 \pm 0.40$ & & & \\
\hline & SC0.5 & 2 & $1.12 \pm 0.38$ & 1 vs. 2 & 5.2 & 0.023 \\
\hline & SC0.5 + M1.25 & 3 & $1.08 \pm 0.33$ & 1 vs. 5 & 2.9 & 0.090 \\
\hline & $\mathrm{SC} 0.5+\mathrm{M} 2.5$ & 4 & $0.80 \pm 0.37$ & 2 vs. 5 & 0.3 & 0.559 \\
\hline & EC0.5 & 5 & $1.40 \pm 0.35$ & 5 vs. 6 & 4.8 & 0.030 \\
\hline & EC1.0 & 6 & $0.37 \pm 0.19$ & 3 vs. 7 & 0.0 & 0.967 \\
\hline & EC0.5 + M1.25 & 7 & $1.06 \pm 0.33$ & 4 vs. 8 & 0.4 & 0.525 \\
\hline & EC0.5 + M2.5 & 8 & $1.09 \pm 0.49$ & 7 vs. 9 & 3.3 & 0.071 \\
\hline & $\mathrm{EC} 1.0+\mathrm{M} 1.25$ & 9 & $0.58 \pm 0.28$ & 6 vs. 10 & 0.1 & 0.740 \\
\hline & EC1.0 + M2.5 & 10 & $0.20 \pm 0.05$ & 1 vs. 10 & 17.9 & $<0.001$ \\
\hline \multirow{10}{*}{ Frass wt. } & Untreated & 1 & $0.46 \pm 0.07$ & & & \\
\hline & SC0.5 & 2 & $0.16 \pm 0.06$ & 1 vs. 2 & 17.2 & $<0.001$ \\
\hline & SC0.5 + M1.25 & 3 & $0.18 \pm 0.04$ & 1 vs. 5 & 6.1 & 0.041 \\
\hline & SC0.5 + M2.5 & 4 & $0.10 \pm 0.04$ & 2 vs. 5 & 2.7 & 0.100 \\
\hline & EC0.5 & 5 & $0.28 \pm 0.06$ & 5 vs. 6 & 8.8 & 0.003 \\
\hline & EC1.0 & 6 & $0.07 \pm 0.02$ & 3 vs. 7 & 0.0 & 0.871 \\
\hline & EC0.5 + M1.25 & 7 & $0.17 \pm 0.06$ & 4 vs. 8 & 0.7 & 0.381 \\
\hline & EC0.5 + M2.5 & 8 & $0.17 \pm 0.06$ & 7 vs. 9 & 4.8 & 0.029 \\
\hline & $\mathrm{EC} 1.0+\mathrm{M} 1.25$ & 9 & $0.10 \pm 0.05$ & 6 vs. 10 & 0.6 & 0.452 \\
\hline & EC1.0 + M2.5 & 10 & $0.09 \pm 0.05$ & 1 vs. 10 & 39.1 & $<0.001$ \\
\hline
\end{tabular}

Progeny adults, total weight loss, frass weight, and total weight loss were all significant for S. oryzae $(F=10.1, \mathrm{df}=9,228, p<0.001, F=2.9, \mathrm{df}=9,225, p=0.003, F=6.2, \mathrm{df}=9,226, p<0.001$, respectively $)$ under the mixed model analysis. In contrast to $R$. dominica, there was progeny production by $S$. oryzae on the treated wheat (Table 2), with significant differences in the orthogonal contrasts only between the deltamethrin SC and EC treatments and the controls, between the 0.5 and 1.0 EC deltamethrin treatments, and between the combination of $1.0 \mathrm{ppm}$ deltamethrin EC with and without the control (Table 2). Progeny production was lowest in treatment 10, which is an indication of a possible additive effect of the deltamethrin EC plus methoprene. However, the speed of efficacy was not measured in this test, but some oviposition in the treatments apparently occurred. Only the contrast between the untreated controls and detamethrin EC at $0.5 \mathrm{ppm}$ and the controls versus the $1.0 \mathrm{ppm}$ plus $2.5 \mathrm{ppm}$ methoprene treatment were significant for total weight loss or frass weight. Other than the possible additive effect of the highest rate of deltamethrin EC with $2.5 \mathrm{ppm}$, there was generally little improvement in efficacy gained by increasing the deltamethrin rate from 0.5 to $1.0 \mathrm{ppm}$ or the inclusion of methoprene.

An analysis was done using the Correlation Procedure in SAS for both R. dominica and S. oryzae by examining all four variables including progeny production, weight loss, frass production, or total damage, over all data. All four variables were significantly positively correlated with each other $(p<0.01)$. The female S. oryzae inserts an egg plug into the grain kernel, and the developing larva is not normally exposed to a residual insecticide. Therefore, methoprene is not generally effective on 
weevils because of the limited larval exposure. Since deltamethrin is a contact insecticide for all insect life stages, it was expected that there would be some efficacy against adult weevils, but, for complete control, adult females should be killed before they can oviposit.

\subsection{Brown Rice}

There was no progeny production or insect damage resulting from the exposure of parental adult $R$. dominica on treated brown rice (Table 3). While progeny production of S. oryzae was generally lower in treatments than in untreated controls, there was considerable variation among the nine treatments. Progeny production of $S$. oryzae appeared to be much greater on brown rice than wheat. Although some values for each of the four analysis variables (progeny production, sample wt. loss, frass weight, and total damage) appear to be numerically different for the analysis variables, the Bonferroni test is conservative and did not show significant differences between treatments. Brown rice is rice with the protective husk removed. Therefore, it is easier for the female weevil to penetrate compared to wheat or rough rice with the protective husk. Previous studies show that $R$. dominica did not develop well on rough rice and may require a crack or split in the hull or husk to gain entry [18-20], which is why we used brown rice for this current study. All four variables were significantly and positively correlated with each other $(p<0.01)$ for both $R$. dominica and S. zeamais on brown rice.

Table 3. Progeny production, total weight loss (WL in \%), and feeding damage (Frass wt. in g) (means $\pm \mathrm{SE}$ ) from exposure of 10 mixed-sex parental adult $S$. oryzae on untreated brown rice and brown rice treated with the insecticide combinations Table 1. $F$ and $p$ values given for selected orthogonal contrasts.

\begin{tabular}{|c|c|c|c|c|c|c|}
\hline & Treatment & $\#$ & Mean \pm SE & Contrast & $F$ & $p$ \\
\hline \multirow{10}{*}{ Progeny } & Untreated & 1 & $154.8 \pm 23.9$ & & & \\
\hline & SC0.5 & 2 & $53.3 \pm 6.3$ & 1 vs. 2 & 36.1 & $<0.001$ \\
\hline & SC0.5 + M1.25 & 3 & $58.5 \pm 7.8$ & 1 vs. 5 & 16.9 & $<0.001$ \\
\hline & SC0.5 + M2.5 & 4 & $77.9 \pm 10.8$ & 2 vs. 5 & 3.6 & 0.085 \\
\hline & EC 0.5 & 5 & $85.4 \pm 12.5$ & 5 vs. 6 & 1.7 & 0.199 \\
\hline & EC1.0 & 6 & $63.7 \pm 11.3$ & 3 vs. 7 & 3.3 & 0.071 \\
\hline & $\mathrm{EC} 0.5+\mathrm{M} 1.25$ & 7 & $89.2 \pm 9.2$ & 4 vs. 8 & 0.1 & 0.741 \\
\hline & EC0.5 + M2.5 & 8 & $83.5 \pm 10.3$ & 7 vs. 9 & 5.1 & 0.024 \\
\hline & $\mathrm{EC} 1.0+\mathrm{M} 1.25$ & 9 & $73.4 \pm 11.4$ & 6 vs. 10 & 0.6 & 0.448 \\
\hline & $\mathrm{EC} 1.0+\mathrm{M} 2.5$ & 10 & $50.8 \pm 5.8$ & 1 vs. 10 & 37.9 & $<0.001$ \\
\hline \multirow{10}{*}{ Total WL } & Untreated & 1 & $5.10 \pm 1.06$ & & & \\
\hline & SC 0.5 & 2 & $2.94 \pm 1.10$ & 1 vs. 2 & 2.5 & 0.115 \\
\hline & SC0.5 + M1.25 & 3 & $3.06 \pm 0.84$ & 1 vs. 5 & 6.1 & 0.014 \\
\hline & SC0.5 + M2.5 & 4 & $3.01 \pm 0.92$ & 2 vs. 5 & 0.8 & 0.371 \\
\hline & EC 0.5 & 5 & $1.70 \pm 1.60$ & 5 vs. 6 & 0.5 & 0.489 \\
\hline & EC1.0 & 6 & $2.67 \pm 0.70$ & 3 vs. 7 & 0.3 & 0.599 \\
\hline & $\mathrm{EC} 0.5+\mathrm{M} 1.25$ & 7 & $2.32 \pm 0.49$ & 4 vs. 8 & 0.1 & 0.888 \\
\hline & EC0.5 + M2.5 & 8 & $2.82 \pm 0.71$ & 7 vs. 9 & 0.1 & 0.792 \\
\hline & $\mathrm{EC} 1.0+\mathrm{M} 1.25$ & 9 & $3.58 \pm 1.71$ & 6 vs. 10 & 0.3 & 0.601 \\
\hline & EC1.0 + M2.5 & 10 & $1.96 \pm 0.43$ & 1 vs. 10 & 5.3 & 0.023 \\
\hline \multirow{10}{*}{ Frass wt. } & Untreated & 1 & $0.76 \pm 0.18$ & & & \\
\hline & SC0.5 & 2 & $0.34 \pm 0.10$ & 1 vs. 2 & 6.3 & 0.013 \\
\hline & SC0.5 + M1.25 & 3 & $0.31 \pm 0.09$ & 1 vs. 5 & 3.9 & 0.050 \\
\hline & SC0.5 + M2.5 & 4 & $0.44 \pm 0.12$ & 2 vs. 5 & 0.3 & 0.588 \\
\hline & EC 0.5 & 5 & $0.43 \pm 0.13$ & 5 vs. 6 & 0.5 & 0.467 \\
\hline & EC1.0 & 6 & $0.30 \pm 0.11$ & 3 vs. 7 & 0.3 & 0.611 \\
\hline & $\mathrm{EC} 0.5+\mathrm{M} 1.25$ & 7 & $0.40 \pm 0.07$ & 4 vs. 8 & 0.1 & 0.791 \\
\hline & EC0.5 + M2.5 & 8 & $0.49 \pm 0.12$ & 7 vs. 9 & 1.0 & 0.314 \\
\hline & $\mathrm{EC} 1.0+\mathrm{M} 1.25$ & 9 & $0.49 \pm 0.17$ & 6 vs. 10 & 0.2 & 0.643 \\
\hline & $\mathrm{EC} 1.0+\mathrm{M} 2.5$ & 10 & $0.22 \pm 0.04$ & 1 vs. 10 & 10.1 & 0.002 \\
\hline
\end{tabular}




\subsection{Corn}

Progeny production of T. castaneum was low on untreated controls possibly because this species is not a primary feeder on stored corn, but, nevertheless, no progeny was produced on the treated corn. Hence, contrasts were not done. There was some variation in insect damage, particularly when the high rate of methoprene was used. This could be attributable to extension of the larval stage, which can occur when larvae of T. castaneum are exposed to IGRs. The treatments involving the EC formulation of deltamethrin, alone or in combination with methoprene, were significantly different from the SC formulation for the two damage variables. Overall, there was little damage in any of the treatments with the deltamethrin EC (Table 4). Progeny production of S. zeamais on corn was variable in all treatments, but the combination of 1.0 ppm deltamethrin EC and 2.5 ppm methoprene gave the lowest progeny and the least amount of weight loss and feeding damage (Table 5).

Table 4. Total weight loss (WL in \%, means $\pm \mathrm{SE}$ ) from exposure of 10 mixed-sex parental adult T. castaneum on corn treated with the insecticide combinations Table 1. F and $p$ values given for selected orthogonal contrasts. Progeny production in untreated wheat was $13.4 \pm 2.4$ and frass weight was $0.41 \pm 0.04 \mathrm{~g}$. No progeny production or frass in the treatments.

\begin{tabular}{ccccccc}
\hline & Treatment & $\#$ & Mean \pm SE & Contrast & $\boldsymbol{F}$ & $p$ \\
\hline Progeny & Untreated & 1 & $13.4 \pm 2.4$ & & & \\
\hline & Untreated & 1 & $1.49 \pm 0.16$ & & & \\
SC0.5 & 2 & $0.34 \pm 0.13$ & 1 vs. 2 & 55.5 & $<0.001$ \\
& SC0.5 + M1.25 & 3 & $0.35 \pm 0.13$ & 1 vs. 5 & 62.8 & $<0.001$ \\
& SC0.5 + M2.5 & 4 & $0.66 \pm 0.29$ & 2 vs. 5 & 0.2 & 0.633 \\
& EC0.5 & 5 & $0.26 \pm 0.07$ & 5 vs. 6 & 0.1 & 0.151 \\
& EC1.0 & 6 & $0.21 \pm 0.06$ & 3 vs. 7 & 1.0 & 0.267 \\
& EC0.5 + M1.25 & 7 & $0.19 \pm 0.04$ & 4 vs. 8 & 0.0 & 0.274 \\
& EC0.5 + M2.5 & 8 & $0.37 \pm 0.18$ & 7 vs. 9 & 1.9 & 0.975 \\
& EC1.0 + M1.25 & 9 & $0.26 \pm 0.06$ & 6 vs. 10 & 1.7 & 0.421 \\
& EC1.0 + M2.5 & 10 & $0.41 \pm 0.15$ & 1 vs. 10 & 48.8 & $<0.001$ \\
\hline
\end{tabular}

Table 5. Progeny production, total weight loss (WL in \%), and feeding damage (Frass wt. in $\mathrm{mg}$ ) (means $\pm \mathrm{SE}$ ) from exposure of 10 mixed-sex parental adult $S$. zeamais on untreated corn and corn treated with the insecticide combinations Table 1. F and $p$ values given for selected orthogonal contrasts.

\begin{tabular}{|c|c|c|c|c|c|c|}
\hline & Treatment & $\#$ & Mean \pm SE & Contrast & $F$ & $p$ \\
\hline \multirow{10}{*}{ Progeny } & Untreated & 1 & $26.4 \pm 5.9$ & & & \\
\hline & SC0.5 & 2 & $10.8 \pm 5.1$ & 1 vs. 2 & 8.5 & 0.004 \\
\hline & SC0.5 + M1.25 & 3 & $7.3 \pm 4.1$ & 1 vs. 5 & 6.0 & 0.156 \\
\hline & SC0.5 + M2.5 & 4 & $10.8 \pm 4.4$ & 2 vs. 5 & 0.2 & 0.633 \\
\hline & EC 0.5 & 5 & $13.4 \pm 5.0$ & 5 vs. 6 & 2.1 & 0.151 \\
\hline & EC1.0 & 6 & $5.7 \pm 3.0$ & 3 vs. 7 & 1.2 & 0.267 \\
\hline & EC0.5 + M1.25 & 7 & $1.4 \pm 1.0$ & 4 vs. 8 & 1.2 & 0.274 \\
\hline & EC0.5 + M2.5 & 8 & $5.0 \pm 2.6$ & 7 vs. 9 & 0.0 & 0.975 \\
\hline & $\mathrm{EC} 1.0+\mathrm{M} 1.25$ & 9 & $2.0 \pm 1.7$ & 6 vs. 10 & 0.7 & 0.403 \\
\hline & $\mathrm{EC} 1.0+\mathrm{M} 2.5$ & 10 & $1.0 \pm 1.1$ & 1 vs. 10 & 22.3 & $<0.001$ \\
\hline \multirow{10}{*}{ Total WL } & Untreated & 1 & $1.12 \pm 0.16$ & & & \\
\hline & SC0.5 & 2 & $0.84 \pm 0.26$ & 1 vs. 2 & 0.8 & 0.377 \\
\hline & SC0.5 + M1.25 & 3 & $0.72 \pm 0.26$ & 1 vs. 5 & 0.8 & 0.386 \\
\hline & SC0.5 + M2.5 & 4 & $0.99 \pm 0.24$ & 2 vs. 5 & 0.0 & 0.987 \\
\hline & EC 0.5 & 5 & $0.85 \pm 0.23$ & 5 vs. 6 & 0.5 & 0.479 \\
\hline & EC1.0 & 6 & $0.63 \pm 0.24$ & 3 vs. 7 & 0.8 & 0.369 \\
\hline & $\mathrm{EC} 0.5+\mathrm{M} 1.25$ & 7 & $0.43 \pm 0.20$ & 4 vs. 8 & 0.5 & 0.465 \\
\hline & $\mathrm{EC} 0.5+\mathrm{M} 2.5$ & 8 & $0.76 \pm 0.30$ & 7 vs. 9 & 0.1 & 0.792 \\
\hline & $\mathrm{EC} 1.0+\mathrm{M} 1.25$ & 9 & $0.39 \pm 0.09$ & 6 vs. 10 & 0.2 & 0.716 \\
\hline & $\mathrm{EC} 1.0+\mathrm{M} 2.5$ & 10 & $0.52 \pm 0.13$ & 1 vs. 10 & 3.8 & 0.054 \\
\hline
\end{tabular}


Table 5. Cont.

\begin{tabular}{ccccccc}
\hline & Treatment & $\#$ & Mean \pm SE & Contrast & $\boldsymbol{F}$ & $p$ \\
\hline & Untreated & 1 & $0.25 \pm 0.11$ & & & \\
SC0.5 & 2 & $0.14 \pm 0.07$ & 1 vs. 2 & 2.7 & 0.104 \\
Frass wt. & SC0.5 + M1.25 & 3 & $0.08 \pm 0.04$ & 1 vs. 5 & 2.3 & 0.132 \\
& EC0.5 & 4 & $0.19 \pm 0.07$ & 2 vs. 5 & 0.0 & 0.904 \\
& EC1.0 & 5 & $0.15 \pm 0.04$ & 5 vs. 6 & 0.7 & 0.994 \\
& EC0.5 + M1.25 & 7 & $0.09 \pm 0.04$ & 3 vs. 7 & 0.0 & 0.316 \\
& EC0.5 + M2.5 & 8 & $0.08 \pm 0.05$ & 4 vs. 8 & 1.0 & 0.922 \\
& EC1.0 + M1.25 & 9 & $0.05 \pm 0.04$ & 7 vs. 9 & 0.0 & 0.805 \\
& EC1.0 + M2.5 & 10 & $0.07 \pm 0.04$ & 6 vs. 10 & 0.6 & 0.363 \\
& & & & & 6.7 & 0.012 \\
\hline
\end{tabular}

\section{Discussion}

Previous studies indicate that neonate $R$. dominica larvae are very susceptible to methoprene applied to different stored grains, even though the exposure time could be very brief before the neonates bore into grain kernels [21]. Although there is no indication of time of death of larvae that were able to bore into a grain kernel, the reduced adult emergence indicates that the neonate absorbs enough of the methoprene so that the exposed larva cannot emerge from the kernel as an adult. R. dominica was also susceptible to the SC formulation of deltamethrin, alone or in combination with methoprene, and there was no apparent loss of efficacy with the new EC formulation. In addition, the new EC formulation was much easier to formulate in water compared to the SC formulation, which made it easier to apply the treatments involving the new EC formulation to the commodity.

There was some evidence that the EC formulation of deltamethrin was more effective than the SC formulation for control of $S$. oryzae on wheat but was less effective on brown rice. This was possibly due to a potential capacity for greater progeny production on brown rice when compared to wheat. Other studies have also shown reduced effectiveness when stored product insects are exposed for short time intervals on grains treated with deltamethrin or exposed on packaging that have deltamethrin incorporated into the laminate layers of the packaging [22-24].

All treatments were effective against $T$. castaneum for 15 months on corn, which was expected since this species is an external feeder and all life stages would be exposed to the insecticide residues. Data also indicate that the new EC formulation may give some level of control of S. zeamais on corn even though additional tests may be necessary due to the low progeny production in untreated controls in the current study. Given the concerns regarding resistance to the fumigant phosphine in the US [25-27], there is a need for increased use of grain protectants in the management programs for stored bulk grains. Protectants such as those evaluated in this study could be combined with other management strategies, including aeration to cool and modify the storage bin temperature. Use of a grain protectant does not preclude the use of phosphine in case fumigation becomes necessary to eliminate an infestation that arises during storage.

In summary, the EC formulation of deltamethrin gave increased efficacy over the current SC formulation for residual control of stored product insects. The registrant of the insecticide could use this data to improve the combination pyrethroid-methoprene combination by substituting the new formulation. It may be beneficial to provide several application rates for the product, depending on primary target species for the protectant application.

\section{Conclusions}

The website states that a conclusion is optional. As a result of reviewer comments, I deleted the Conclusion and moved the paragraph to the Discussion section. The paper was accepted without a conclusion section.

Funding: This research was by Central Life Sciences through a Trust Agreement. 
Acknowledgments: The author acknowledges the excellent technical assistance provided by B. Barnett during the study. We also thank Central Life Sciences (Schaumberg, IL, USA) for providing the methoprene and the deltamethrin SC and EC formulations used in the study and for partial financial support of the research. This paper reports the results of research only. The mention of trade names or commercial products in this publication is solely for the purpose of providing specific information and does not imply recommendation or endorsement by the USDA. The USDA is an equal opportunity employer and provider.

Conflicts of Interest: I declare no conflict of interest. The funder had no role in the design of the study, in the collection, analyses, or interpretation of data, in the writing of the manuscript, or in the decision to publish the results.

\section{References}

1. Mason, L.J.; McDonough, M. Biology, behavior, and ecology of stored grain and legume insects. In Stored Product Protection, Circular S156; Hagstrum, D.H., Phillips, T.W., Cuperus, G.W., Eds.; Kansas State University: Manhattan, KS, USA, 2012; pp. 233-242. Available online: http:/ / www.bookstore.ksre.ksu.edu/pubs/S156. pdf (accessed on 4 February 2019).

2. Hagstrum, D.W.; Flinn, P.W.; Reed, C.; Phillips, T.W. Ecology and IPM of Insects at Grain Elevators and Flat Storages. Biopestic. Int. 2010, 61, 1-20.

3. Arthur, F.H.; Ondier, G.O.; Siebenmorgen, T.J. Milling quality of rough rice exposed to increasing Rhyzopertha dominica (F.) population levels. J. Stored Prod. Res. 2012, 48, 137-142. [CrossRef]

4. Hagstrum, D.W.; Reed, C.; Kenkel, P. Management of stored wheat insect pests in the USA. Integ. Pest Manag. Rev. 1999, 4, 127-142. [CrossRef]

5. Arthur, F.H.; Subramanyam, B. Chemical Control in Stored Products. In Stored Product Protection, Circular S156; Hagstrum, D.H., Phillips, T.W., Cuperus, G.W., Eds.; Kansas State University: Manhattan, KS, USA, 2012; pp. 95-100. Available online: http://www.bookstore.ksre.ksu.edu/pubs/S156.pdf (accessed on 4 February 2019).

6. Arthur, F.H.; Casada, M.E. Directional flow of summer aeration to manage insect pests in stored wheat. Appl. Eng. Agric. 2012, 26, 115-122. [CrossRef]

7. Arthur, F.H.; Throne, J.E.; Maier, D.E.; Montross, M.D. Initial cooling cycles for corn stored in the southern United States: Aeration strategies based on weather data. Am. Entomol. 1998, 44, 118-123. [CrossRef]

8. Arthur, F.H.; Yang, Y.; Wilson, L.T.; Siebenmorgen, T.J. Feasibility of automatic aeration for insect pest management for rice stored in east Texas. Appl. Eng. Agric. 2008, 24, 345-350. [CrossRef]

9. Arthur, F.H.; Yang, Y.; Wilson, L.T. Utilization of a web-based model for aeration management in stored rough rice. J. Econ. Entomol. 2011, 104, 702-708. [CrossRef] [PubMed]

10. Arthur, F.H.; Casada, M.E. Temperature stratification and insect pest populations in stored wheat with suction versus pressure aeration. Appl. Eng. Agric. 2016, 32, 849-860.

11. Yang, Y.; Wilson, L.T.; Arthur, F.H.; Wang, J.; Jia, C. Regional analysis of bin aeration as an alternative to insecticidal control for post-harvest management of Sitophilus oryzae (L.) and Rhyzopertha dominica (F.). Ecol. Model. 2017, 359, 165-181. [CrossRef]

12. Lui, S.; Arthur, F.H.; Van Gundy, D.; Phillips, T.W. Combination of methoprene and controlled aeration to manage insects in stored wheat. Insects 2016, 7, 25. [CrossRef]

13. Flinn, P.W.; Subramanyam, B.; Arthur, F.H. Comparison of aeration and spinosad for suppressing insects in stored wheat. J. Econ. Entomol. 2004, 97, 1465-1473. [CrossRef] [PubMed]

14. Arthur, F.H.; Hagstrum, D.W.; Flinn, P.W.; Reed, C.; Phillips, T.W. Insect populations in grain residues associated with commercial Kansas grain elevators. J. Stored Prod. Res. 2006, 42, 226-239. [CrossRef]

15. McKay, T.J.; White, A.L.; Starkus, L.; Arthur, F.H.; Campbell, J.F. Seasonal patterns of stored-product insects at a rice mill. J. Econ. Entomol. 2017, 110, 1366-1376. [CrossRef] [PubMed]

16. Tilley, D.R.; Casada, M.E.; Langemeier, M.R.; Subramanyam, B.; Arthur, F.H. Temporal changes in stored-product insect populations associated with boot, pit, and load-out areas of grain elevators and feed mills. J. Stored Prod. Res. 2017, 73, 62-73. [CrossRef]

17. Kavallieratos, N.G.; Athanassiou, C.G.; Arthur, F.H. Efficacy of deltamethrin against stored-product beetles at short exposure intervals or on a partially-treated rice mass. J. Econ. Entomol. 2015, 108, 1416-1421. [CrossRef] [PubMed] 
18. Arthur, F.H.; Starkus, L.; Smith, C.M.; Phillips, T.W. Methodology for determining susceptibility of rough rice to Rhyzopertha dominica (L.) and Sitotroga cerealella (Olivier). J. Pest Sci. 2013, 86, 499-505. [CrossRef]

19. Chanbang, Y.; Arthur, F.H.; Wilde, G.E.; Throne, J.E. Hull characteristics as related to susceptibility of different varieties of rough tice to Rhyzopertha dominica (F.), the lesser grain borer (Coleoptera: Bostrichidae). J. Stored Prod. Res. 2008, 44, 205-212. [CrossRef]

20. Kavallieratos, N.G.; Athanassiou, C.G.; Arthur, F.H.; Throne, J.E. Cracked hulls affect population development of Rhyzopertha dominica in rough rice. J. Insect Sci. 2012, 12, 38. [CrossRef]

21. Arthur, F.H. Efficacy of methoprene for multi-year protection of stored wheat, brown rice, rough rice and corn. J. Stored Prod. Res. 2016, 68, 85-92. [CrossRef]

22. Kavallieratos, N.G.; Athanassiou, C.G.; Arthur, F.H. Effectiveness of insecticide-incorporated bags to control stored-product beetles. J. Stored Prod. Res. 2016, 70, 18-24. [CrossRef]

23. Scheff, D.S.; Arthur, F.H.; Campbell, J.F. Fecundity of Tribolium castaneum and Tribolium confusum adults after exposure to deltamethrin packaging. J. Pest. Sci. 2018, 91, 717-725. [CrossRef]

24. Paudual, S.; Opit, G.P.; Arthur, F.H.; Bingham, G.Z.; Gautam, S.G. Contact toxicity of deltamethrin against Tribolium castaneum (Coleoptera: Tenebrionidae), Sitophilus oryzae (Coleoptera: Curculionidae), and Rhyzopertha dominica (Coleoptera: Bostrichidae) adults. J. Econ. Entomol. 2016, 109, 1943-1950.

25. Opit, G.P.; Phillips, T.W.; Aikins, M.J.; Hasan, M.M. Phosphine resistance in Tribolium castaneum and Rhyzopertha dominica from stored wheat in Oklahoma. J. Econ. Entomol. 2012, 105, 1104-1107. [CrossRef] [PubMed]

26. Gautam, S.G.; Opit, G.P.; Hosoda, E. Phosphine resistance in adult and immature life stages of Tribolium castaneum (Coleoptera: Tenebrionidae) and Plodia interpunctella (Lepidoptera: Pyralidae) Populations in California. J. Econ. Entomol. 2016, 109, 2025-2533. [CrossRef] [PubMed]

27. Konemann, C.K.; Hubhachen, Z.; Opit, G.P.; Bajrachayra, N.S. Phosphine Resistance in Cryptolestes ferrugineus (Coleoptera: Laemophloeidae) collected from grain storage facilities in Oklahoma, USA. J. Econ. Entomol. 2017, 110, 1377-1383. [CrossRef] [PubMed]

(C) 2019 by the author. Licensee MDPI, Basel, Switzerland. This article is an open access article distributed under the terms and conditions of the Creative Commons Attribution (CC BY) license (http://creativecommons.org/licenses/by/4.0/). 